\title{
Various Problems in Oxygen-evolution Reaction Catalysts in Alkaline Conditions and Perovskites Utilization
}

\author{
Jin Goo Lee ${ }^{\dagger}$ \\ School of Chemistry, University of St Andrews, St Andrews, Fife, KY16 9ST, UK

\section{저온형 알칼라인 산소발생반응의 문제점과 perovskites촉매 개발 동향} \\ 이진구 ${ }^{\dagger}$ \\ School of Chemistry, University of St Andrews, St Andrews, Fife, KY16 9ST, UK
}

(Received May 14, 2019; Revised June 20, 2019; Accepted June 20, 2019)

\begin{abstract}
s
Alternative energy sources to the systems using hydrocarbon fuels have been actively developed due to exhaustion of fossil fuels and issue of global warming by $\mathrm{CO}_{2}$. Fuel cells have attracted great attentions to solve these issues as electricity can be produced with product of clean $\mathrm{H}_{2} \mathrm{O}$ by using $\mathrm{H}_{2}-\mathrm{O}_{2}$ as a fuel. Besides, using reverse reactions make it possible to produce $\mathrm{H}_{2}$ and $\mathrm{O}_{2}$ gas from electrolysis of water. There are various fuel cells systems depending on the types of electrolyte, and in this mini-reviews, the main aim is to focus on perovskite oxides as a catalyst for oxygen-evolution reactions in alkaline electrolysis and its potential to application of alkaline electrolysis systems.
\end{abstract}

Keywords: oxygen-evolution reaction, perovskite, alkaline electrolysis cells, catalysts, non-stoichiometry

연료전지는 다양한 연료를(수소 또는 탄화수소 계) 직 접 전기에너지로 전환할 수 있는 전기발생장치로 에너지 효율이 상당히 높고 전기생산 반응을 통해 생성되는 부산 물이 오직 물이기 때문에 최근 대두되는 $\mathrm{CO}_{2}$ 에 의한 지 구 온난화의 측면에서도 상당히 좋은 대체에너지 발생장 치라 할 수 있다. 이러한 연료전지 중에서 알칼라인 연료 전지는 가장 오래되고 발전된 연료전지로서 에너지 효율 이 약 $70 \%$ 에 달하며(전해전지의 수전해 효율 역시 약
$70 \%$ 에 달함), 이미 다양한 분야에 실제로 적용되어 사용 되어져 왔다. ${ }^{1-3)} \mathrm{NASA}$ 의 아폴로 시리즈 미션에서 1960 년 중반까지 전기를 생산하는 장치로서 사용되어진 일례 로 보면, 상당히 오래전에 개발되고 오랜 기간동안 발전 되어 왔음을 알 수 있다. 그러나, 다른 차세대 연료전지 가 관심을 모으면서 연구개발의 속도 현저히 줄어드는 시 기가 찾아오기도 했었다. 예로서, proton-exchange electrolyte membrane fuel cells (PEMFC)은 General 
Proton-exchange membrane

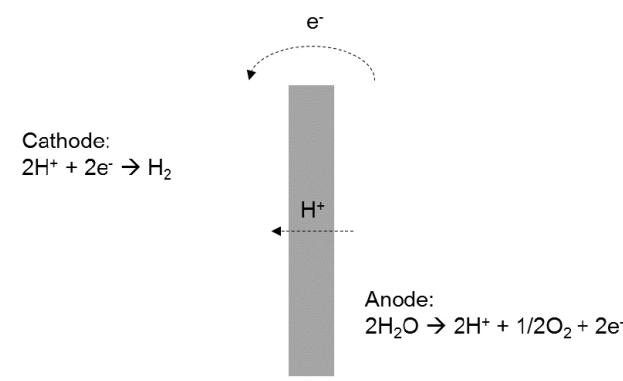

Anion-exchange membrane

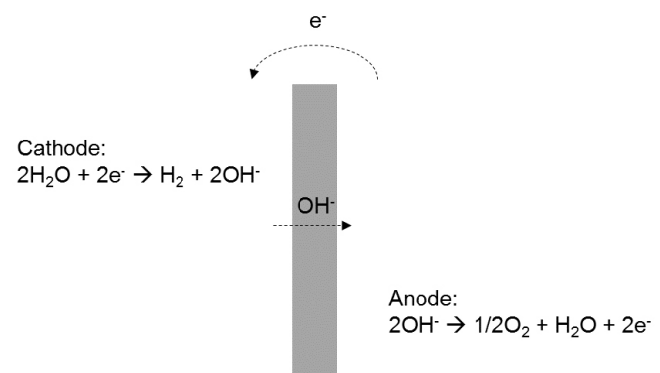

Fig. 1. Schematic diagram for water splitting using proton-exchange/anion-exchange membrane

Electricproton의 Willard Thomas Grubb 과 Leonard Niedrach에 의해 개발되었으며, 이들은 sulfonated polystyrene의 기존에 전해막을 Nafion ionomer로 대 체하면서 효율을 상당히 크게 향상시켰다. 전해막의 사용 은 시스템의 간소화를 이끌었고, proton의 빠른 전달 속 도로 인해서 1960년 이후 기존의 alkaline fuel cell (AFC)을 사용하던 NASA는 PEMFC로 대체하기에 이르 렀다. Anion exchange membrane이 계속적으로 개발 이 되어지고 있지만 상대적으로 proton보다 큰 이온반경 으로 전달속도에서는 proton-exchange membrane에 아직 미치지 못하고 있어, 매우 중요한 시스템 간소화의 측면에서 계속적인 연구가 필요한 분야라고 사료된다.

산성조건의 $\mathrm{PEMFC}$ 에서는 전해질속의 많은 proton 으로 인해 상대적으로 산소환원반응의 활성화 에너지가 크게 요구되며, 반대로 염기성 조건에서는 전해질 속의 높은 $\mathrm{OH}^{-}$농도로 강한 $\mathrm{OH}$ 결합에 의해 hydrogen oxidation 반응에서의 activation energy가 크게 나타 난다. ${ }^{4-6)}$ 수전해 반응에 대한 기본적인 모식도는 Fig. 1 과 같이 나타낼 수 있으며, proton-exchange membrane 과 anion-exchange membrane의 사용에 대한 다른 수 전해 반응을 확인할 수 있다.

Alkaline electrolysis cells (AEC)를 통한 수전해 반 응에서는 oxygen evolution reaction (OER)에서 큰 overpotential을 보여주며, 화학반응은 다음 식 (1)과 같 이 나타낼 수 있다.

$$
4 \mathrm{OH}^{-} \rightarrow \mathrm{O}_{2}+2 \mathrm{H}_{2} \mathrm{O}+4 \mathrm{e}^{-}
$$

촉매의 측면에서 살펴보면 두 연료전지 및 수전해 모두
매우 낮은 온도에서 $\left(\left\langle 100{ }^{\circ} \mathrm{C}\right)\right.$ 운전이 되기 때문에 수소의 산화/환원반응과 산소의 환원/산화반응을 위해 platinum $(\mathrm{Pt})$ 와 같은 희귀금속의 사용이 강요된다. 주 로 $\mathrm{IrO}_{2}$ 또는 $\mathrm{RuO}_{2}$ 가 대표적인 알칼라인 조건에서 $\mathrm{OER}$ 촉매로서 알려져 있으며, 높은 가격으로 인해 상용화에 대한 큰 걸림돌이 되고 있다. 또한, 이러한 $\mathrm{IrO}_{2}$ 와 $\mathrm{RuO}_{2}$ 는 OER반응동안 과산화과정을 통해 알칼라인 전해액에 dissolution되는 경향이 크게 나타나 내구성의 측면에서 도 단점으로 작용한다. 그러나 산성조건의 $\mathrm{PEMFC와는}$ 다르게 최근 값싼 다양한 전이금속/전이금속산화물 촉매 들이 염기성 조건에서 안정된 성능을 보여주는 것이 알려 짐에 따라 $\mathrm{AFC} /$ alkaline electrolysis cells (AEC)에서 다양한 촉매들에 대한 특성 및 성능에 대한 연구가 다시 활발히 진행이 되게 되었다. AEC에서 oxygenevolution 촉매들 중 대표적인 것으로는 single metal/ metal oxides, metal-metal alloys, layered double

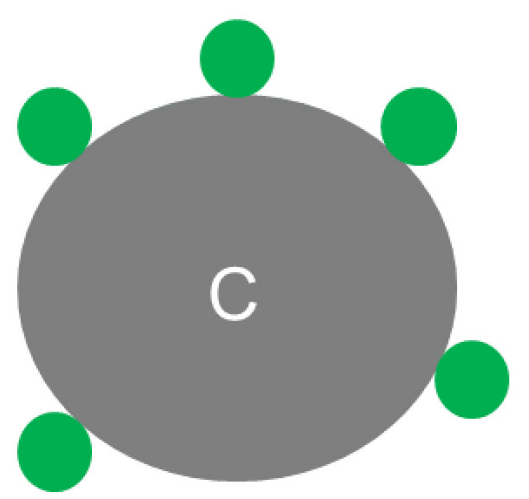

Fig. 2. Typical structure of OER catalysts in alkaline solution 


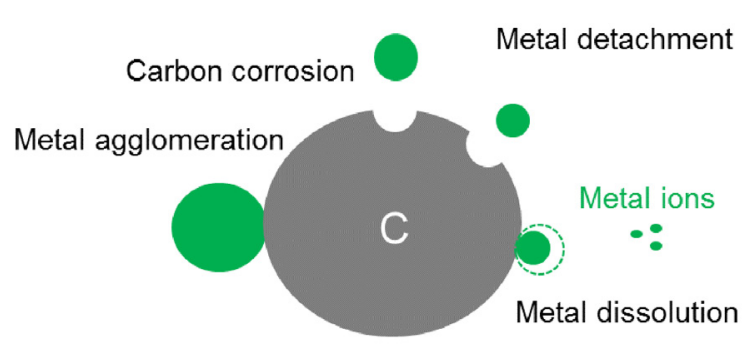

Fig. 3. Various problems in typical OER catalysts during OER reactions

hydroxides (LDH), perovskites, spinel, 그리고 다른 organometallic 물질들이 있다.

알칼라인 촉매의 기본적인 구조는 Fig. 2에서 보여주 는 것과 같이 전이금속 또는 전이금속 산화물과 카본의 복합체로 구성된다. 카본은 전기전도체로서 역할을 할 뿐 만 아니라 높은 표면적으로 인해 카본 그 자체로의 촉매 특성을 지니고 있어 대부분의 저온형 촉매에 지지체로서 활용되고 있다.

그러나 이러한 기본적인 촉매구조는 다양한 문제점들 을 보여주고 있다(Fig. 3). ${ }^{8}$ 이섯번째로 carbon corrosion 문제이며, 약 $0.2 \mathrm{~V}$ 이상의 낮은 potential에서도 carbon corrosion이 시작이 될 수 있으며 이 문제점은 높은 voltage영역으로 갈수록 점점 가속된다. 이로 인한 가장 큰 문제점은 촉매로서 사용되는 전이금속류가 지지체인 carbon으로부터 떨어져 촉매의 기능을 상실하고 OER에 서의 activity가 크게 감소하는데 있다고 할 수 있다. 다 양한 산화물 지지체들에 대한 연구들이 진행이 되고 있지 만, 현재까지는 carbon을 대체할 만한 지지체가 개발되 지 않은 상태이다. 적절한 지지체의 조건은 다음과 같이 나열할 수 있다.

1. High electronic conductivity

2. High surface area

3. Strong interaction with metal catalysts

4. Action as a catalyst or a promotor (Minor)

이러한 문제점 외에도 산성조건에서 보다는 그 속도가

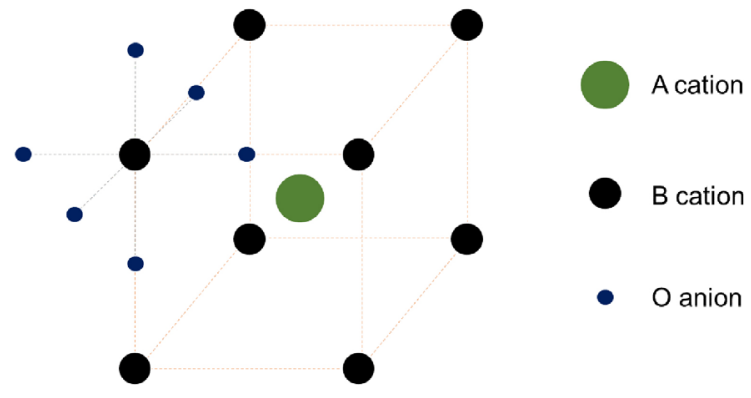

Fig. 4. Crystal structures of perovskite materials 이러한 perovskite 구조의 형성/타입 또는 안정성은 tolerance factor에 의해 영 향을 크게 받으며 다음과 같이 나타낼 수 있다. (2)

느리다고는 하지만 여전히 metal의 dissolution문제가 존재한다. 일반적으로 알칼라인 수전해 장치는 $6 \mathrm{M}$ 이상 의 매우 강한 알칼리 분위기에서 운전이 되기 때문에 이 러한 metal dissolution에 대한 문제도 개선이 필요하 다고 할 수 있다. 마지막으로는 metal agglomeration 이 있는데, 이는 metal과 carbon사이의 결합력에 크게 영향을 받는다. OER반응에서 redox cycle을 겪는 동안 약한 결합을 가지는 metal nanoparticle들은 서로 결합 하여 점점 큰 입자가 되어가며 촉매활성면적이 감소된 다. 이를 위해 strong metal-support interaction (SMSI)을 형성하기 위한 많은 연구들도 진행이 되고 있 는 상황이다. 이러한 문제점을 해결하기 위한 흐름 중 하 나로서 perovskites물질에 대한 연구가 활발하게 진행 되고 있다.

Perovskite는 기본적으로 $\mathrm{ABO} 3$ 의 화학식을 가지는 산화물질로서, 다음 Fig. 4와 같이 나타낼 수 있다. A-site는 주로 lattice의 코너에 위치하며 alkaline earth 또는 rare earth elements들이 위치한다. B-site 는 lattice의 중심에 위치하며 $3 \mathrm{~d}, 4 \mathrm{~d}, 5 \mathrm{~d}$ transition metal elements들이 사용된다.

$$
\mathrm{t}=(\mathrm{rA}+\mathrm{rO}) / \sqrt{2}(\mathrm{rB}+\mathrm{rO})
$$

t는 tolerance factor, $r A$ 는 $A$-site cation의 ionic radius, $\mathrm{rB}$ 는 $\mathrm{B}$-site cation의 ionic radius, 그리고 $\mathrm{rO}$ 는 anion의 ionic radius를 의미한다.

기본적으로 높은 내산/알칼리 특성을 가지고 있으며, impurity에 의해 전기적인 특성이 크게 달라지며, 전이 
금속을 구조에 포함하고 있기 때문에 다양한 분야의 촉매 로서 활용 가능성이 매우 커 오래전부터 폭 넓은 분야에 서 활용 및 연구개발이 진행되고 있다. 이러한 perovskite 구조의 산화물질을 염기성 조건에서 oxygen-evolution 에 대한 촉매로서 활용하기 위해 시도한 것은 최근이 아 니며, 연구들은 perovskites의 activity에 대한 지표와 화학적 연결성의 확인에 있었다. Bockrisd와 Otagawa 의 연구에 따르면 $\mathrm{MO}$ 에서 $\mathrm{Mz}-\mathrm{OH}$ 의 antibonding orbital의 occupancy가 증가되면 electrocatalytic activity가 증가할 수 있다고 보고하였다. ${ }^{10)}$ Rossmeisl과 공동연구자들은 oxygen ions과 hydroxyl ions이 $\mathrm{metal} / \mathrm{metal}$ oxide와 결합하는 결합에너지는 volcano 와 같은 연결성을 가지고 있으며, binding energy를 통 해 다향한 metal/metal oxide의 OER에 대한 activity를 예측할 수 있다고 보고하였다. ${ }^{11)}$ 최근 Suntivich와 공동 연구자들은 다양한 perovskite물질에 대해 OER반응을 측정하였고, transition metal ions의 표면에 eg orbital 의(일반적으로 $\sigma$-bonding을 표면 흡착 anion과 형성) occupancy가 OER activity에 큰 영향을 줄 수 있다는
것을 확인하였다. 이러한 경향은 역시 volcano plot형태 로 나타낼 수 있으며, 현재 perovskte의 activity descriptor중 하나로 활용되고 있다. ${ }^{12)}$ Jong Suk과 그 연구자들은 perovskites구조의 lattice oxygen이 OER 에 참여하며, 가역적으로 반응에 참여하는 산소 빈자리를 통해 이러한 표면 lattice oxygen이 OER반응에서의 intermediated product형성을 촉진한다고 보고하고 있 다. ${ }^{13)}$ 이러한 이론들 이외에 다양한 이론들이 발표되고 있는 가운데, 다양한 perovskite물질에 대한 실험적 $\mathrm{OER}$ 반응에 대한 연구도 활발하게 진행이 되고 있다.

Perovskite물질의 catalytic activity는 stoichiometry 에 의해 크게 영향을 많이 받는다. 일반적으로 소량의 impurity를 도입하여 defects (e.g. oxygen vacancy)를 강제로 생성하여 촉매반응에 대한 촉매활성점으로 이용 하는 경향이 있다. 또한, 이러한 non-stoichiometry에 의해 전기적 특성(e.g. electronic conductivity)이 크게 달라지기 때문에 이러한 방법을 이용하여 알칼라인 조건 에서 높은 전기전도성을 가지는 support 및 catalyst역 할을 할 수 있는 perovskite물질을 개발하는 것도 가능하 a

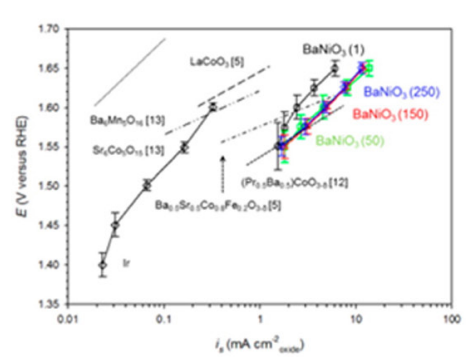

C

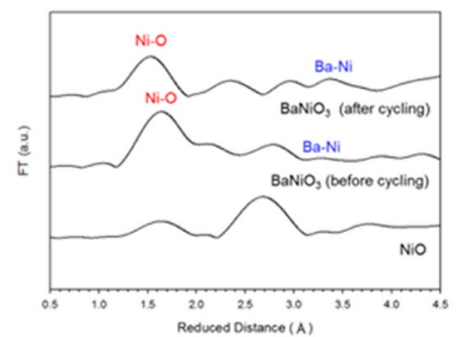

b

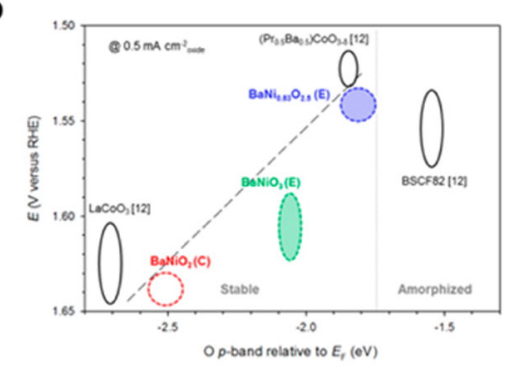

d

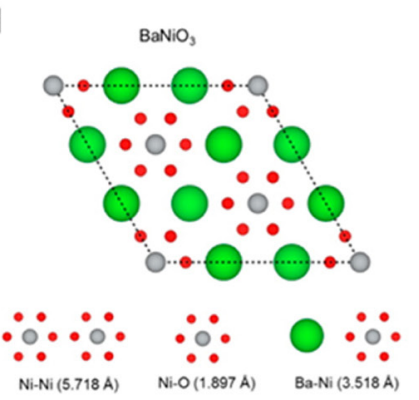

e

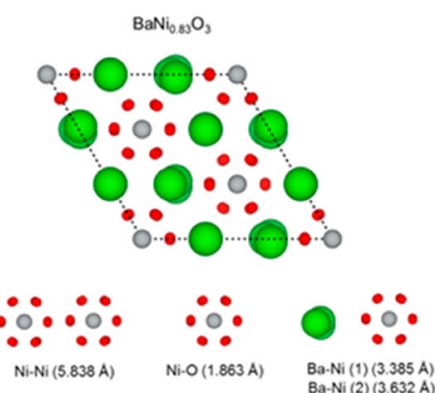

Fig. 5. Difference in OER activity depending on change from $\mathrm{BaNiO}_{3}$ to $\mathrm{BaNi}_{0.83} \mathrm{O}_{2.5 .}{ }^{14)}$ Copyright $(C) 2016$ American Chemical Society 
다고 할 수 있다. Non-stoichiometry를 이용한 많은 연 구들이 있고, 그 중 최근 $\mathrm{SrIrO}_{3}$ 촉매를 적용하여 높은 OER성능을 보여주었다. Seitz와 그 연구자들은 OER cycling동안 $\mathrm{SrIrO}_{3}$ 에서 anatase $\mathrm{IrO}_{2}$ 가 segregation되 어 $\mathrm{IrO}_{2} / \mathrm{SrIrO}_{3}$ 형태의 복합체 형태를 띄게 되며 산성조 건은 물론 염기성 조건에서 높은 성능을 보여주었다고 보 고하였다. ${ }^{5}$ 특히, 알칼라인 조건에서는 $\mathrm{IrO}_{2}$ 와 비교하여 낮은 overpotential과 높은 current density를 보여주어 상당한 개선을 이뤄냈다. 문헌에 따르면 $\mathrm{Sr}$ 의 leaching 이 OER cycling동안 나타났고 이것이 $30 \mathrm{~min}$ 정도 지속 이 되어 그 후에는 평형상태에 도달한다고 하였다. $\mathrm{Sr}$ 분 리현상은 $\mathrm{SrIrO}_{3}$ 의 표면구조를 변화시키고 nonstoichiometric 형태를 띄는 Sr deficient perovskite가 표면에 형성될 것이다. Alkaline earth metal은 액체상 태의 전해액속에서 쉽게 dissolution될 수 있고 이것은 alkaline earth metal을 주로 A-site에 가지는 perovskite구조 물질에서 좋지 않게 작용할 수도 있을 것 이다. 이러한 관점에서 A-site deficient perovskites는 alkaline earth metal의 침출현상을 방지할 수 있는 하 나의 방안이 될 수도 있을 것이다. 대표적으로 solid oxide fuel cells (SOFCs)의 경우 주로 전극물질을 perovskite구조를 가지는 물질을 사용하며, 흔히 고온 영역에서 alkaline earth metal의 분리현상이 나타나는 문제점을 보인다. 많은 연구자들 사이에 A-site 결함을 가지는 non-stoichiometric perovskites가 이러한 분 리현상을 막을 수 있다고 보고되는 것과 같이 염기성 조 건의 OER반응에서 역시 어느정도 적용이 가능하다고 할 수 있다.

또 따른 non-stoichiometric perovskites의 예시로 서는 $\mathrm{BaNiO}_{3}$ 가 $\mathrm{OER}$ 반응을 거치며 결정구조의 변화가 일어나게 되고 non-stoichiometric $\mathrm{BaNi}_{0.83} \mathrm{O}_{2,5}$ 형태의 $\mathrm{Ni}$ 와 O vacancies 형성에 의해 OER반응이 크게 향상될 수 있다는 것을 보여준다. ${ }^{6)}$

Fig. 5에서 보여주듯이, 결정구조의 변화로 인해 $\mathrm{Ni}-\mathrm{O}$ 의 interatomic distance가 $\sim 1.92 \AA$ 에서 $\sim 1.84$ $\AA$ 으로 OER cycling동안 감소하는 것을 알 수 있다. O p-band에너지 센터가 Fermi energy로 가까울수록
$\mathrm{OER}$ 활성도가 향상되는 경향이 있다. 실험적 결과들을 바탕으로 한 DFT calculation에서 O p-band energy 센터는 $\mathrm{BaNiO}_{3}, \mathrm{BaNiO}_{2}$, and $\mathrm{BaNi}_{0.83} \mathrm{O}_{2.5}$ 순으로 $-2.14,-2.49$, and $-1.79 \mathrm{eV}$ 로 나타났으며, $\mathrm{BaNi}_{0.83} \mathrm{O}_{2.5}$ 가 가장 높은 OER activity를 가지는 것이 어느 정도 설 명이 가능하다 할 수 있다. 이와 같이, nonstoichiometry를 이용하여 OER activity를 크게 향상시 킬 수 있을 뿐만 아니라, 더 나아가 전기전도성도 확보 를 하게 된다면 촉매와 지지체 역할을 동시에 할 수 있 는 multi-functional 물질을 개발할 수도 있다고 할 수 있다.

Bifunctional catalysts에 대한 연구도 perovskite물 질을 이용하여 많이 진행이 되고 있다. Yamada와 그 연 구자들은 manganese quadruple perovskites $\mathrm{CaMn}_{7} \mathrm{O}_{12}$ 와 $\mathrm{LaMn}_{7} \mathrm{O}_{12}$ 의 합성에 성공하였고 이 촉매들 은 OER과 ORR반응 모두 상당히 좋은 촉매 활성도를 보 여준다고 보고하였다. ${ }^{15)} \mathrm{AMnO}_{3}$ 가 $\mathrm{AMn}_{7} \mathrm{O}_{12}$ 의 형태로 결 정구조가 변화하면서 높은 OER/ORR반응을 보여주는 것으로 이 역시 non-stoichiometric perovskite의 좋은 예시라고 할 수 있다. 높은 OER성능에 대한 이유로서는 $\mathrm{A}^{\prime}$-와 B-site의 Mn ion들과 연결되어 있는 흡착 반응물 사이에 직접적인 $\mathrm{O}-\mathrm{O}$ bond형성으로 서술하고 있다. Jung과 그 연구자들은 $\mathrm{La}$ 이 도입된 $\mathrm{La}_{\mathrm{x}}\left(\mathrm{Ba}_{0.5} \mathrm{Sr}_{0.5}\right)_{1-}$ ${ }_{x} \mathrm{Co}_{0.8} \mathrm{Fe}_{0.2} \mathrm{O}_{3-8}$ 물질을 $\mathrm{OER}$ 반응 촉매로서 적용하였고, $0.7 \mathrm{La}$ 의 경우 가장 높은 성능과 안정성을 가진다고 보고 하였다. ${ }^{16)}$ 이러한 높은 촉매활성도는 B-site 양이온의 electronic structure와 nano-scale 접근에 의한 것이 라 서술하고 있다. 특히, nano-scale 접근법은 촉매활성 도를 향상시키는데 매우 효율적인 방법이며 연구자들은 약 $50 \mathrm{~nm}$ 크기의 나노입자 perovskite를 합성하는데 성 공하였다. 높은 비표면적과 표면에 형성된 수많은 결함들 은 확실히 촉매활성도의 향상에 큰 역할을 하는 것으로 여겨지며, micro 또는 nano 구조체가 촉매활성도의 향 상에 큰 기여를 할 수 있다는 것을 보여준다. Nonstoichiometric perovskite에 대한 마지막 예시로서 $\mathrm{Kim}$ 과 그 연구자들은 $\mathrm{Ca}_{2} \mathrm{Mn}_{2} \mathrm{O}_{3}$ 형태의 oxygendeficient perovskite가 OER반응에서 매우 활성도가 높 
다고 보고하고 있다. ${ }^{17)}$ 이 연구 역시 초기의 형태는 $\mathrm{CaMnO}_{3}$ 를 취하고 있으며, 낮은 농도의 환원분위기에 노 출되었을 때, $\mathrm{Ca}_{2} \mathrm{Mn}_{2} \mathrm{O}_{3}$ 의 oxygen-deficient perovskite형태로 변화한다고 서술한다. 상당히 큰 비율 의 산소 빈자리를 통해 높은 성능이 도출될 수 있었다고 예상된다.

위에서 보여준 예시들과 같이 perovskite물질을 활용 한 알칼라인 조건에서의 OER반응 향상은 매우 큰 가능 성을 보여주며, 특히 non-stoichiometry에 의한 결함형 성은 촉매활성의 향상에 큰 영향을 미칠 수 있다고 할 수 있다. 따라서, perovskites물질을 촉매로 선정할 때 stoichiometry의 최적화 역시 고려되어야 한다고 사료된 다. 이 외에도 다양한 perovskite 구조를 가지는 물질들 이 OER반응의 촉매로서 연구/개발되고 있으며 수많은 연구결과들이 보고되어 있다. 언급되어진 factor들 이외 에도 물질의 표면적, 촉매의 표면 facets, 그 외에 다른 다양한 인자들이 촉매의 활성도에 영향을 줄 수 있으며, 촉매의 설계방법이 매우 중요하다고 할 수 있다. 미세구 조에서 역시 perovskite를 활용한 촉매에서 큰 부분을 차 지하는데 일반적으로 perovskite는 높은 온도에서 합성 이 가능하기 때문에 비표면적이 상당히 낮게 분포한다. 따라서 저온합성법(sol-gel, co-precipitation, 또는 hydro/solvothermal)에 의한 비표면적 향상이 촉매활 성 향상에 중요하다고 할 수 있다. 지금까지 본 글에서 서 술한 내용은 OER에 대한 기본적인 문제점과 perovskite 촉매들의 단편적인 예시만을 보여주었으며, 여러가지 다 양한 인자들을 고려하여 활성도를 예측할 수 있는 하나의 지표로 만드는 연구가 현재 알칼라인 조건에서의 OER촉 매분야에서 시급한 과제로 여겨진다.

\section{참고문헌}

1. A. J. Appleby and F. R. Foulkes, "Fuel cell handbook" United States (1988)

2. A. B. Stambouli and E. Traversa, "Fuel cells, an alternative to standard sources of energy" Renewable and Sustainable Energy Reviews, 6, 295-304 (2002)

3. M. S. Whittingham, R. F. Savinell, T. Zawodzinski, "Introduction: batteries and fuel cells" Chemical
Reviews, 104, 4243, (2004)

4. D. J. Kim, M. J. Jo, and S. Y. Nam, "A review of polymer - nanocomposite electrolyte membranes for fuel cell application" Journal of Industrial and Engineering Chemistry, 21, 36-52 (2015)

5. G. Gahleitner, "Hydrogen from renewable electricity: An international review of power-to-gas pilot plants for stationary applications" International Journal of Hydrogen Energy, 38, 2039-2061 (2013)

6. Y. Wang, J. Qiao, R. Baker, and J. Zhang, "Alkaline polymer electrolyte membranes for fuel cell applications" Chem. Soc. Rev., 42, 5768-5787 (2013)

7. J. O. M. Bockris and T. Otagawa, "Mechanism of oxygen evolution on perovskites" J. Phys. Chem. 87, 2960-2971 (1983)

8. J. Larminie, and A. Dicks "Fuel Cell Systems Explained" John Wiley \& Sons Ltd (2003)

9. E. Antolini, "Carbon supports for low-temperature fuel cell catalysts" Applied Catalysis B: Environmental, 88, 1-24, (2009)

10. I. C. Man, H. Su, F. Calle-Vallejo, H. A. Hansen, J. I. Martínez, N. G. Inoglu, J. Kitchin, T. F. Jaramillo, J. K. Nørskov, and J. Rossmeisl, "Universality in Oxygen Evolution Electrocatalysis on Oxide Surfaces" ChemCatChem, 3, 1159 - 1165 (2011)

11. J. Suntivich, K. J. May, H. A. Gasteiger, J. B. Goodenough, and Y. Shao-Horn, "A Perovskite Oxide Optimized for Oxygen Evolution Catalysis from Molecular Orbital Principles" Science, 334, 1383-1385 (2011)

12. J. S. Yoo, X. Rong, Y. Liu, and A. M. Kolpak, "Role of Lattice Oxygen Participation in Understanding Trends in the Oxygen Evolution Reaction on Perovskites" ACS Catal. 8, 4628-4636 (2018)

13. L. C. Seitz, C. F. Dickens, K. Nishio, Y. Hikita, J. Montoya, A. Doyle, C. Kirk, A. Vojvodic, H. Y. Hwang, J. K. Norskov, and T. F. Jaramillo, "A highly active and stable $\mathrm{IrO}_{\mathrm{x}} / \mathrm{SrIrO}_{3}$ catalyst for the oxygen evolution reaction" Science, 353, 1011-1014 (2016)

14. J. G. Lee, J. Hwang, H. J. Hwang, O. S. Jeon, J. Jang, O. Kwon, Y. Lee, B. Han, and Y. Shul, "A New Family of Perovskite Catalysts for Oxygen-Evolution Reaction in Alkaline Media: $\mathrm{BaNiO}_{3}$ and $\mathrm{BaNi}_{0.83} \mathrm{O}_{2,5}$ " J. Am. Chem. Soc. 138, 3541-3547 (2016)

15. I. Yamada, H. Fujii, A. Takamatsu, H. Ikeno, K. Wada, H. Tsukasaki, S. Kawaguchi, S. Mori, S. Yagi, "Bifunctional Oxygen Reaction Catalysis of Quadruple 
Manganese Perovskites” Adv. Mater. 29, 1603004 (2017)

16. J. Jung, M. Risch, S. Park, M. G. Kim, G. Nam, H. Jeong, Y. Shao-Horn, and J. Cho, "Optimizing nanoparticle perovskite for bifunctional oxygen electrocatalysis" Energy Environ. Sci., 9, 176-183 (2016)

17. J. Kim, X. Yin, K. Tsao, S. Fang, and Hong Yang, $\quad \mathrm{Ca}_{2} \mathrm{Mn}_{2} \mathrm{O}_{5}$ as Oxygen-Deficient Perovskite Electrocatalyst for Oxygen Evolution Reaction" J. Am. Chem. Soc. 136, 14646-14649 (2014)

\section{•이진구}

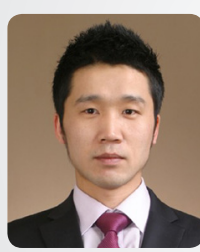

( 2015년 연세대학교 화공생명공학과 박사

○ 2015년-2017년 연세대학교 화공생명공학과 Post-Doc

- 2017년-현재 University of St Andrews 화학과 Research Fellows 